\title{
Study of Histomorphological Characteristics and it's Correlation with Clinical, Biochemical, Serological and Immunohistochemical Parameters in Incidentally Detected Hepatitis B Patients
}

\author{
Rakesh Kumar Gupta ${ }^{1}$, Puja Sakhuja ${ }^{2 *}$, Shahajad Ali $^{2}$, Sidharth Srivastava ${ }^{3}$, \\ Barjesh Chand Sharma ${ }^{3}$ and Amarender Singh Puri ${ }^{3}$
}

\begin{abstract}
'Department of Pathology, Chattisgarh Institute of Medical Sciences, Bilaspur, Chattisgarh, India.
${ }^{2}$ Departments of Pathology Govind Ballabh Pant Institute of Postgraduate Medical Education and Reseach, New Delhi, India.

${ }^{3}$ Departments of Gastro-enterology Govind Ballabh Pant Institute of Postgraduate Medical Education and Reseach, New Delhi, India.
\end{abstract}

\section{ABSTRACT}

Background: India lies in intermediate endemicity zone for hepatitis B virus (HBV) infection and constitutes the second largest global pool of HBV infection worldwide. Hepatitis B has a varied clinical presentation ranging from clinically asymptomatic state to cirrhosis and hepatocellular carcinoma. A significant liver injury can occur, without accompanying elevation in alanine transaminase (ALT) and HBV DNA levels, especially in incidentally detected asymptomatic hepatitis B subjects (IDAHS). Hence, a role of liver biopsy to be incorporated with other investigations is debatable, but important to initiate antiviral therapy.

We explored correlation between histomorphological outcomes with various clinical, biochemical, serological and immunohistochemical parameters in IDAHS.

Methods and Material: Total 113 patients were consecutively selected over a period of 4.5 years. Serological work-up for HBsAg, Anti$\mathrm{HBeAg}$, Anti-HBeAb, Anti-HBcAb, and HBV DNA levels were done as per resources. A liver biopsy was done in each patient after a written consent. Ishak's scoring system was used to assess histological parameters. Immunohistochemistry (IHC) was done for $\mathrm{HBs} \mathrm{Ag}$ and $\mathrm{HBcAg}$. Appropriate statistical tests were applied.

Results: The mean age of the patients was 30 years with a male to female ratio of 3:1. A higher necro-inflammatory activity (NIA $>3$ ) correlated with high ALT ( $>40 \mathrm{U} / \mathrm{l})$, HBV DNA ( $>105$ copies $/ \mathrm{ml})$ and fibrosis $(\mathrm{F} \geq 2)$. HBeAg-positive patients had significantly higher NIA and HBV DNA levels. Anti-HBeAb delineated association with ALT ( $\leq 40 \mathrm{U} / 1)$ and low HBV DNA but more severe fibrosis $(\mathrm{F} \geq 2)$. Steatotic changes were noted in $52.2 \%$ biopsies. IHC for HBsAg and $\mathrm{HBeAg}$ showed positivity in $82.7 \%$ and $39.2 \%$ of cases respectively with a significant correlation between membranous pattern of HBsAg staining and serum HBV DNA levels.

Conclusion: IDAHS represent tip of the iceberg of major HBV infection reservoir. A liver biopsy is a useful additional tool with other parameters to further tailor the therapy in such asymptomatic patients.

Keywords: Hepatitis B Virus, Hepatitis B Surface Antigen, Hepatitis B e Antigen, Viral DNA, Alanine Transaminase.

\section{Introduction}

Worldwide prevalence of hepatitis B virus (HBV) varies significantly among different population. In India, prevalence of hepatitis B surface antigen (HBsAg) in general population ranges from $2 \%$ to $7 \%$, which lies in intermediate endemicity zone. ${ }^{[1]}$ Of the estimated 360 million worldwide chronic carrier, India accounts for about 50 million, forming the second largest global pool of chronic HBV infections. ${ }^{[2]}$ In India transmission is mostly acquired through childhood horizontal spread due to sub-optimal hygiene and crowded living conditions and perinatal transmission of infection from mother to infants is not an important route. ${ }^{[1]}$ Hepatitis B disease has a varied clinical presentation ranging from clinically asymptomatic state to the development of cirrhosis and hepatocellular carcinoma depending upon the phase. Patient may present (a) in a state of immune tolerance, (b) HBeAg-positive chronic HBV, (c) HBeAg-negative chronic HBV, or (d) as an inactive HBsAg carrier. ${ }^{[3,4]}$ Chronic HBV (both HBeAgpositive and $\mathrm{HBeAg}$-negative) patients have a relatively higher chance of developing various complications. ${ }^{[5]}$

All major liver organizations, such as the American association for the study of liver diseases (AASLD), the European association for the study of the liver (EASL), and the Asian-Pacific association for the study of the liver (APASL), consistently recommend therapy for patients with liver damage and complications. ${ }^{[6,7]}$ However, these recommendations for treatment of chronic hepatitis B 
patients are not always appropriate to apply in most of the developing countries. ${ }^{[8]}$

Although incidentally-detected asymptomatic HBsAgpositive subjects (IDAHS) appear healthy at the time of presentation, varying proportions have evidence of liver disease on biopsy. ${ }^{[9]}$ Though ALT, HBV DNA levels and $\mathrm{HBeAg}$ status determination serve as important means to predict the extent of disease in these patients, nevertheless a liver biopsy plays an important role to ascertain amount of injury and also decision making to plan antiviral treatment. ${ }^{[10-12]}$

The limited number of liver biopsies in IDAHS patients, more so in developing countries and the scarce literature on correlation between various histological indices with serological and viral markers provided us insight for this study.

We started this study with an aim to correlate various measurable histological events with serological and viral parameters in IDAHS patients to guide clinicians in deciding appropriate antiviral therapy.

\section{Methods and Materials}

This paper is approved by departmental review board. Total 137 consecutive patients presented in the liver clinic of Gatroenterology outpatient department of the institute over a period of 4.5 years from January, 2010 to June, 2014 were included in the study. All patients were apparently healthy without any features of liver-related diseases during their first visit to the hospital. These patients came to the hospital for a routine check-up before foreign trip (as asked by embassy officials for visa), during pregnancy, after household contacts, health personnel after accidental exposure, referred from blood bank etc. All the patients who found to be HBsAg positive were asked to follow different public health measures. Also, patients were requested to seek HBsAg testing after 6 months and to visit in case of any illness. When HBsAg was detected 6 months after the first test, the patients were regarded as being chronically infected with HBV, and enrolled.

Patients with the past history of chronic liver disease or decompensation of liver function, alcohol consumption more than $20 \mathrm{~g} /$ day, hepatotoxic drug, any systemic illnesses such as diabetes mellitus, and those having coinfection with HIV or hepatitis C virus were excluded from the study. Physical parameters such as body mass index and waist hip ratio was measured in each patient at the time of registration. Ultrasonography report, if available was also included.

Biochemical and Serological Tests: Routine haemogram, lipid profile, serum insulin, fasting blood sugar and liver function tests were done on all patients. The cutoff for the upper limit of normal (ULN) was ALT > $40 \mathrm{U} / \mathrm{l}$. HBsAg was assessed using a commercial ELISA kit (Diasorin, Fallugia, Italy). $\mathrm{HBeAg}$ and anti-HBe antibody were tested using an ELISA kit (Abbott Labs, Chicago, Ill., USA).

Serum HBV DNA was quantified using an RT-PCR kit (Amplicon HBV Monitor Assay, Roche Molecular Systems, Calif.,USA). The lower limit of detection was 250 copies of HBV DNA $/ \mathrm{ml}$. A level of $>10^{5}$ copies $/ \mathrm{ml}$ was considered as active/replicative infection.

Liver biopsy: A prior written informed consent was taken from all the patients before liver biopsy. Percutaneous liver biopsies from all the patients were obtained under local anesthesia using 16G Tru-Cut needles (Cardinal Health, McGaw Park, Ill, USA). The liver biopsies at least $1 \mathrm{~cm}$ long with $\geq 6$ portal triads were included. The liver biopsies were fixed in $10 \%$ buffered formalin and four micron sections were stained with hematoxylin and eosin (H\&E), masson's trichrome and orcein stains. Necro-inflammatory activity (NIA) and fibrosis stage were assessed using the Ishak's scoring system. Extent of hepatitis was graded as mild (NIA $\leq 3$ ), and significant (NIA $\geq 4$ ), while fibrosis was staged as follows: F0, no fibrosis; F1, mild portal fibrosis with/without septa; F2, marked portal fibrosis with/without septa; F3, portal fibrosis with occasional P-P bridging septa; F4, portal fibrosis with numerous bridging septa; F5, marked bridging fibrosis with occasional nodules; F6, cirrhosis. Immunohistochemistry (IHC) was performed on $4 \mu$ thick formalin fixed, paraffin-embedded sections using antibodies directed against HBsAg (Neomarker) and $\mathrm{HBcAg}$ (Neomarker). Antigen retrieval for $\mathrm{HBsAg}$ was done in a microwave oven using citrate buffer at $\mathrm{pH}$ 6.0 and streptavidin biotin conjugate immunoperoxidase method was used. For each batch, appropriate positive controls were taken and for negative controls primary antibodies were omitted.

Statistical Analyses: Data were analyzed using SPSS version 17 software package (SPSS, Inc., Chicago, IL). Statistical analyses were performed using Chi square and Fisher exact tests for categorical variables. Student $t$ test or 1-way analysis of variance was used for group comparisons of parametric quantitative data. Differences were considered significant at $\mathrm{p}<0.05$.

\section{Results}

Baseline characteristics of patients (Table 1). Of the 137 patients, 113 were found eligible after putting exclusion criteria's. The mean age of the patient was 30 years; 84 $(74.3 \%)$ were male and the other $29(25.7 \%)$ were female. $\mathrm{HBeAg}$ status did not revealed significant correlation with age. The median level of serum ALT was 47 U/1 (range 11- 
$790 \mathrm{U} / 1)$. ALT was higher than the cut off for the ULN in $65.6 \%$ subjects. Of the 113 patients, liver biopsies showed variable amount of portal inflammation in all, ground glass hepatocytic changes in $74(65.4 \%)$, and lobular inflammation in 92 (81.4\%) (Table 2). Both ground glass changes with concurrent lobular inflammation were noted in $57(50.4 \%)$ patients. Interface activity, focal lymphoid aggregate and ductal injury was noted in $8(7 \%), 13$ $(11.5 \%)$ and $7(6.1 \%)$ biopsies respectively. Abdominal ultra-sonography reports were available in 24 patients, $5(20.8 \%)$ of which showed abnormal echotexture. High NIA delineated significant correlation with high ALT levels, HBV DNA and fibrosis (Table 3). HBeAg status was known in 90 patients, of which 43 (47.7\%) were HBeAg-positive.

Anti-HBe antibody (Anti-HBeAb) levels were investigated in 58 patients, $30(51.7 \%)$ of which showed positivity (Table 4). Anti-HBeAb positivity was more common in patients with low ALT $(\leq 40 \mathrm{U} / \mathrm{l})$ and HBV DNA levels $\left(<10^{5}\right.$ copies $\left./ \mathrm{ml}\right)$ but more severe fibrosis $(\mathrm{F} \geq 2)$.

Anti $\mathrm{HBc}$ antibody (Anti-HbCAb) was measured only in 17 patients, $12(70.5 \%)$ of which were positive.
Comparatively higher HBV DNA levels were noted in HBeAg-positive against HBeAg-negative patients (71.4 vs. $28.6 \%, \mathrm{p}<0.0001$ ) (Table 5).

Similarly, a higher NIA was seen among HBeAg-positive patients. Also, in HBeAg-positive group, 21 (48.8\%) patients had both higher serum ALT and HBV DNA levels, in comparison to HBeAg-negative group, 6 (12.8\%) and the difference was statistically significant ( $p$ value $<0.0001$ ).

Steatotic changes were noted in 59/113 (52.2\%) patients, which varied considerably ranging from $5 \%$ to $85 \%$ of the hepatocytes with a meadian of $10 \%$. Steatosis amount and pattern did not showed differences with HBeAg status. IHC for $\mathrm{HBsAg}$ and $\mathrm{HBcAg}$ showed positivity in 67/81(82.7\%) and $33 / 84(39.2 \%)$ of the biopsies respectively (Figure 1). Both the antibodies showed three pattern of the staining including cluster, diffuse and scattered. In addition to cytoplasmic positivity, HBsAg also showed membranous staining in 24/67 (35.8\%) of the biopsies. HBcAg revealed both nuclear and cytoplasmic positivity in 10/33 (39.2\%) of the cases. The membranous pattern of HBsAg showed a positive correlation with the serum levels of HBV DNA $(p=0.018)$.

Table 1: Baseline characteristics of the hepatitis B patients

\begin{tabular}{|c|c|c|}
\hline \multicolumn{2}{|l|}{ Parameters } & Values \\
\hline \multicolumn{2}{|c|}{ No of patients } & 113 \\
\hline \multicolumn{2}{|c|}{ Age, years } & $29.9 \pm 11.9$ \\
\hline \multicolumn{2}{|c|}{ Male } & $74.3 \%$ \\
\hline \multicolumn{2}{|c|}{ Female } & $25.7 \%$ \\
\hline \multirow{2}{*}{$\mathrm{HBeAg}$} & positive & $47.8 \%$ \\
\hline & negative & $52.2 \%$ \\
\hline \multirow{2}{*}{ Anti-HBeAb } & positive & $51.7 \%$ \\
\hline & negative & $48.3 \%$ \\
\hline \multirow{2}{*}{ Anti-HBcAb } & positive & $70.6 \%$ \\
\hline & negative & $29.4 \%$ \\
\hline \multirow{2}{*}{ ALT levels } & Normal & $34.4 \%$ \\
\hline & Raised & $65.6 \%$ \\
\hline \multirow{2}{*}{ HBV DNA levels } & $\leq 10^{5}($ copies $/ \mathrm{ml})$ & $41.2 \%$ \\
\hline & $>10^{5}($ copies $/ \mathrm{ml})$ & $58.8 \%$ \\
\hline \multirow{2}{*}{ Ultrasound } & Normal echotexture & $79.2 \%$ \\
\hline & Coarse echotexture & $20.8 \%$ \\
\hline
\end{tabular}


Table 2: Histopathological characteristics, Ishak's staging and grading and immunohistochemistry (HBsAg \& HBcAg) of the liver biopsies in the hepatitis B patients.

\begin{tabular}{|c|c|c|}
\hline \multicolumn{2}{|l|}{ Parameters } & Values \\
\hline \multicolumn{2}{|c|}{ Portal inflammation } & $100 \%$ \\
\hline \multicolumn{2}{|c|}{ Ground glass changes } & $65.5 \%$ \\
\hline \multicolumn{2}{|c|}{ Lobular inflammation } & $81.4 \%$ \\
\hline \multicolumn{2}{|c|}{ Interface activity } & $7.1 \%$ \\
\hline \multicolumn{2}{|c|}{ Lymphoid aggregate } & $11.5 \%$ \\
\hline \multicolumn{2}{|c|}{ Duct injury } & $6.2 \%$ \\
\hline \multirow{2}{*}{ NIA score } & $1-3$ & $51.9 \%$ \\
\hline & $>3$ & $48.1 \%$ \\
\hline \multirow{2}{*}{ Fibrosis stage } & $0-1$ & $65.9 \%$ \\
\hline & $\geq 2$ & $34.1 \%$ \\
\hline \multirow{3}{*}{ Steatosis $(\%)(n=59)$} & $1-9 \%$ & $37.3 \%$ \\
\hline & $10-30 \%$ & $44.0 \%$ \\
\hline & $>30 \%$ & $18.7 \%$ \\
\hline \multicolumn{2}{|c|}{ HBsAg positive (Total/C/C+M/M) } & $82.7 \% / 64.1 \% / 32.8 \% / 2.9 \%$ \\
\hline \multicolumn{2}{|c|}{ HBcAg positive (Total/N/C+N) } & $39.2 \% / 69.6 \% / 30.3 \%$ \\
\hline
\end{tabular}

Table 3: Correlation of NIA with ALT levels, serum HBV DNA and fibrosis.

\begin{tabular}{|l|c|c|c|}
\hline Parameters & NIA $(\leq 3)$ & NIA ( $\geq 4)$ & P value \\
\hline ALT $(\geq 1 U L N)$ & $54.1 \%$ & $78.4 \%$ & 0.0001 \\
\hline HBV DNA $\left(\geq 10^{5}\right.$ copies/ml) & $44.1 \%$ & $66.7 \%$ & 0.04 \\
\hline HBeAg+ & $22.9 \%$ & $71.9 \%$ & 0.0001 \\
\hline Fibrosis stage (High $\geq 2)$ & $10.7 \%$ & $65.8 \%$ & 0.0001 \\
\hline Anti-HBeAb+ & $70.0 \%$ & $45.5 \%$ & 0.09 \\
\hline
\end{tabular}

Table 4: Comparison of histological, serological and virological parameters between HBeAg-positive and HBeAg-negative patients.

\begin{tabular}{|c|c|c|c|c|}
\hline \multicolumn{2}{|l|}{ Parameters } & HBeAg-positive & HBeAg-negative & $P$ value \\
\hline \multicolumn{2}{|c|}{ No of patients $(n=90)$} & 43 & 47 & \\
\hline \multirow[t]{2}{*}{ ALT levels } & Normal & $28.9 \%$ & $46.7 \%$ & \multirow[t]{2}{*}{0.98} \\
\hline & Raised & $71.1 \%$ & $53.3 \%$ & \\
\hline \multirow[t]{2}{*}{ HBV DNA levels } & $\leq 10^{5}($ copies $/ \mathrm{ml})$ & $14.6 \%$ & $66.7 \%$ & \multirow[t]{2}{*}{0.0001} \\
\hline & $>10^{5}$ (copies/ml) & $85.4 \%$ & $33.3 \%$ & \\
\hline \multirow[t]{2}{*}{ NIA score } & $1-3$ & $32.3 \%$ & $75 \%$ & \multirow[t]{2}{*}{0.0001} \\
\hline & $>3$ & $67.7 \%$ & $25 \%$ & \\
\hline \multirow[t]{2}{*}{ Fibrosis stage } & $0-1$ & $60.0 \%$ & $73.0 \%$ & \multirow[t]{2}{*}{0.26} \\
\hline & $\geq 2$ & $40.0 \%$ & $27.0 \%$ & \\
\hline \multirow{3}{*}{$\begin{array}{l}\text { Steatosis }(\%) \\
(n=46)\end{array}$} & $1-9 \%$ & $74.4 \%$ & $63.8 \%$ & \multirow[t]{3}{*}{0.17} \\
\hline & $10-30 \%$ & $23.3 \%$ & $23.4 \%$ & \\
\hline & $>30 \%$ & $2.3 \%$ & $12.8 \%$ & \\
\hline \multirow[t]{2}{*}{ Anti-HBeAb } & Positive & $29.6 \%$ & $80.0 \%$ & \multirow[t]{2}{*}{0.0001} \\
\hline & Negative & $70.4 \%$ & $20.0 \%$ & \\
\hline
\end{tabular}


Table 5: Comparison of histological, serological and virological parameters between AntiHBeAb-positive and AntiHBeAbnegative patients

\begin{tabular}{|c|c|c|c|c|}
\hline \multicolumn{2}{|l|}{ Parameters } & AntiHBeAb positive & AntiHBeAb negative & $P$ value \\
\hline \multicolumn{2}{|c|}{ No of patients $(n=58)$} & 30 & 28 & \\
\hline \multirow{2}{*}{ ALT levels } & Normal & $48.3 \%$ & $18.5 \%$ & \multirow{2}{*}{0.01} \\
\hline & Raised & $51.7 \%$ & $81.5 \%$ & \\
\hline \multirow{2}{*}{ HBV DNA levels } & $\leq 10^{5}($ copies $/ \mathrm{ml})$ & $63.0 \%$ & $7.1 \%$ & \multirow{2}{*}{0.0001} \\
\hline & $>10^{5}$ (copies/ml) & $37.0 \%$ & $92.9 \%$ & \\
\hline \multirow{2}{*}{ NIA score } & $1-3$ & $58.3 \%$ & $33.3 \%$ & \multirow{2}{*}{0.10} \\
\hline & $>3$ & $41.7 \%$ & $66.7 \%$ & \\
\hline \multirow{2}{*}{ Fibrosis stage } & $0-1$ & $56.0 \%$ & $89.5 \%$ & \multirow{2}{*}{0.01} \\
\hline & $\geq 2$ & $44.0 \%$ & $10.5 \%$ & \\
\hline \multirow{3}{*}{$\begin{array}{l}\text { Steatosis }(\%) \\
(n=29)\end{array}$} & $1-9 \%$ & $46.7 \%$ & $35.7 \%$ & \multirow{3}{*}{0.72} \\
\hline & $10-30 \%$ & $46.7 \%$ & $50.0 \%$ & \\
\hline & $>30 \%$ & $6.7 \%$ & $14.3 \%$ & \\
\hline \multirow{2}{*}{$\mathrm{HBeAg}$} & Positive & $28.6 \%$ & $79.2 \%$ & \multirow{2}{*}{0.0001} \\
\hline & Negative & $71.4 \%$ & $20.8 \%$ & \\
\hline
\end{tabular}

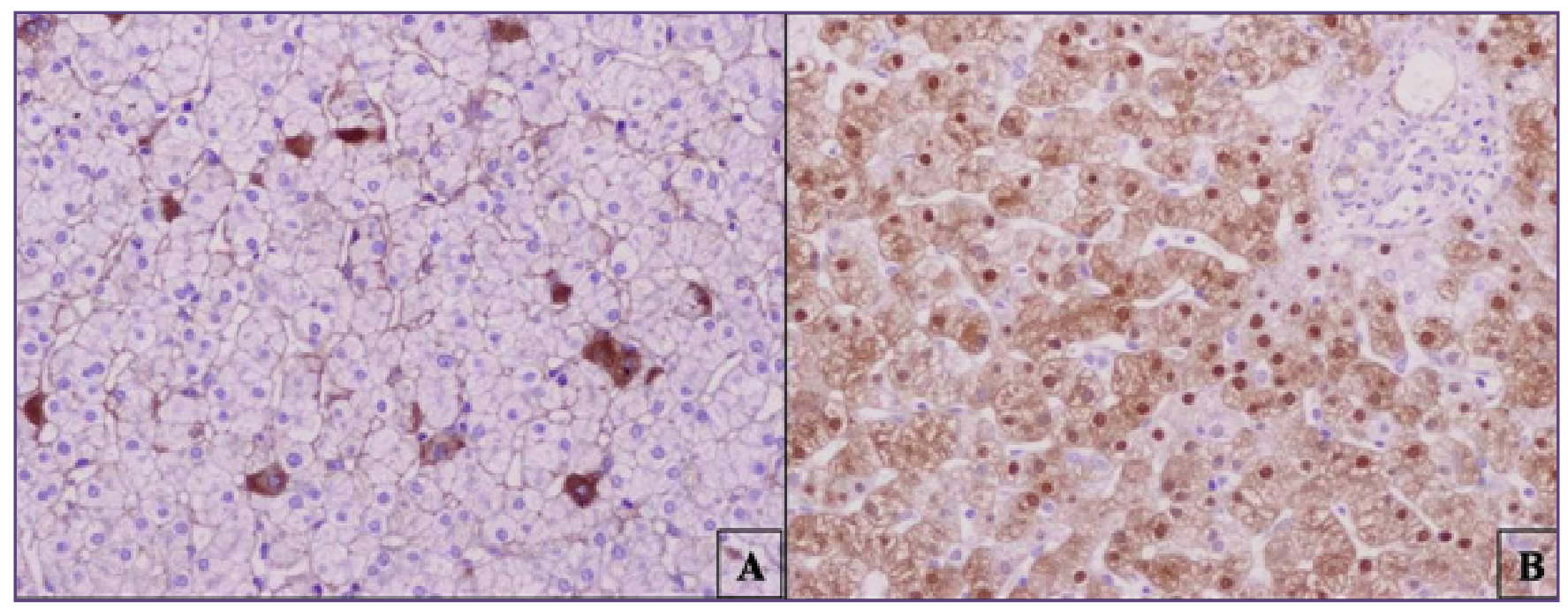

Fig. 1: Photomicrographs showing cytoplasmic and membranous immunopositivity for HBsAg (A) and nuclear \& cytoplasmic positivity for HBcAg (B) (X 200 each).

\section{Discussion}

India is the second largest global pool of chronic hepatitis $\mathrm{B}$ (CHB) carriers. Because of socio-economic hurdles, millions of these patients are unaware of HBV infection and serve as an important source of reservoir. There are no effective screening system and treatment guidelines for these patients. Since these patients are asymptomatic, they do not seek medical attention till complications develop. We endeavor to find significance of each histological change in the liver biopsy including portal inflammation, ground glass change, lobular inflammation, lymphoid aggregate, duct injury and steatosis separately. We found ground glass change in $\sim 65 \%$ of the biopsies which is a characteristic feature in CHB. Interestingly, in this study, we found steatosis in $52 \%(\mathrm{n}=59)$ of the biopsies, out of which $62 \%$ had steatosis $\geq 10 \%$ and 11 patients among them with $>30 \%$ steatosis, which is more characteristic of chronic hepatitis $\mathrm{C}$ (CHC). However, no significant association was found between extent of steatosis and NIA.

The higher positivity rate in liver biopsies for HBsAg $(82.7 \%)$ than for $\mathrm{HBcAg}$ (39.2\%), explain selective secretion of HBsAg and, inactivation of more immunogenic portions like core genes during the viral genome integration, thus evading immunologic attack and elimination. ${ }^{[13]}$ 
Mukhopadhya et al described scattered, cluster and sheet patterns of staining both for HBsAg and $\mathrm{HBcAg}$, which were also seen in this study. ${ }^{[14]}$ Earlier, membranous staining of HBsAg has been reported to be associated with active viral replication and disease activity. ${ }^{[15]}$ We found a significant positive correlation of membranous $\mathrm{HBsAg}$ staining with higher serum levels of HBV DNA ( $p=0.018)$.

In our study, 21 (18.5\%) patient had high ALT (above ULN), along with HBV DNA $\left(>10^{5}\right)$ and NIA $(\geq 4)$ which is higher than $8.5 \%$ described in study by Mahtab et al. ${ }^{[12]}$

This is the first study which explored the role of other immunological factors such as Anti-HBeAb and Anti$\mathrm{HBcAb}$ in the pathogenesis of CHB. Anti-HBeAb showed a positive correlation with normal ALT and low HBV DNA levels $\left(<10^{5}\right.$ copies $\left./ \mathrm{ml}\right)$ but with distinctly higher fibrosis stage $(\mathrm{F} \geq 2)(\mathrm{p}<0.016)$.

Viral load, HBeAg status, ALT levels and NIA are the important indicators of liver damage and serve to guide treatment. ${ }^{[6,7]}$ In this study, we found a good correlation between these parameters. The extent of liver injury however does not always correlate with the ALT and HBV DNA levels. ${ }^{[16]}$ Also, since there is a complex interplay between HBV, hepatocytes and host immune system, these markers fluctuate markedly in the course of disease. ${ }^{[12]}$ ALT levels are also influenced by body mass index (BMI), metabolism and time of measurement. ${ }^{[17,18]}$ Earlier, studies supported that even in immunotolerant phase and with relatively normal ALT levels significant liver fibrosis and necro-inflammatory changes can occur. ${ }^{[19,}{ }^{20]}$ Recently, Kumar et al showed that IDAHS display variable amount of liver injury with normal level of biochemical (ALT), virological (HBV DNA) and immunological (HBeAg) markers. ${ }^{[11]}$

In India and other developing nations, HBV infection mostly acquired in early childhood, reflecting a longer period of insult to hepatocytes in comparison to developed countries, where most of the HBV infections trigger in adult life. Early onset of infection, itself explain more likelihood of severe liver injury than western population. So, EASL, and AASLD recommendations, based on western population with main consideration of biochemical and virological factors to commence antiviral therapy, should not be extrapolated in the developing world.

About $10 \%$ patients with HBV DNA levels $<10^{5}$ copies $/ \mathrm{ml}$ showed significant fibrosis $(\mathrm{F} \geq 2)$. Earlier, also patients with $<10^{5}$ copies/ml have shown to carry risk for progression to cirrhosis or hepatocellular carcinoma. ${ }^{[21,22]}$ So, the cut-off of $>10^{5}$ copies $/ \mathrm{ml}$ for HBV DNA levels may not be justified in many patients.
So, we encourage and support EASL \& Lok and McMahon recommended treatment guidelines based on serum ALT levels, HBV DNA levels, and $\mathrm{HBeAg}$ status but a liver biopsy can be corroborated to further tailor the therapy. Rather, a personalized approach, considering regional, demographic, racial and socio-economic factors, may benefit maximum in these patients. Also, there is a need to sensitize healthcare cadre and governments towards the epidemic level of HBV infection in developing countries, and develop a global system of screening programme to curtail the dreadful further spread of this infection.

\section{Acknowledgment:}

We would like to thanks Dr Tanu Anand for her support in statistical analysis.

\section{References:}

1. Elizabeth W. Hwang, Ramsey Cheung. Global Epidemiology of Hepatitis B Virus (HBV) Infection. N A J Med Sci. 2011;4(1):7-13.

2. Datta $\mathrm{S}$. An overview of molecular epidemiology of hepatitis B virus (HBV) in India. Virol J. 2008;5:156.

3. Ganem D, Prince AM. Hepatitis B virus infection-natural history and clinical consequences. N Engl J Med. 2004;350(11):1118-29.

4. Fattovich G, Bortolotti F, Donato F. Natural history of chronic hepatitis B: special emphasis on disease progression and prognostic factors. J Hepatol. 2008;48(2):335-52.

5. Keeffe EB, Dieterich DT, Han SH et al. A treatment algorithm for the management of chronic hepatitis B virus infection in the United States: 2008 update. Clin Gastroenterol Hepatol. 2008;6(12):1315-41.

6. Lok AS, McMahon BJ. Chronic hepatitis B: update 2009. Hepatology. 2009;50(3):661-2.

7. Liaw YF, Leung N, Kao JH et al. Chronic Hepatitis B Guideline Working Party of the Asian-Pacific Association for the Study of the Liver. Asian-Pacific consensus statement on the management of chronic hepatitis B: a 2008 update. Hepatol Int. 2008;2(3):263-83.

8. Akbar SM, Hiasa Y, Mishiro S, Onji M. Treatment of hepatitis B virus-infected patients: utility of therapeutic recommendations in developing countries. Expert Opin Pharmacother. 2009;10(10):1605-14.

9. Chandra R, Kapoor D, Agarwal SR, Malhotra V, Sakhuja P, Sarin SK. Profile of asymptomatic chronic HBV infection in India. Indian J Med Res. 2002;116:50-7.

10. Papatheodoridis GV, Manesis EK, Manolakopoulos S et al. Is there a meaningful serum hepatitis B virus DNA cutoff level for therapeutic decisions in hepatitis B e antigennegative chronic hepatitis B virus infection? Hepatology. 2008;48(5):1451-9.

11. Kumar M, Sarin SK, Hissar S et al. Virologic and histologic features of chronic hepatitis B virus-infected asymptomatic 
patients with persistently normal ALT. Gastroenterology. 2008;134(5):1376-84.

12. Al-Mahtab M, Rahman S, Akbar SM, Kamal M, Khan MS. Clinical use of liver biopsy for the diagnosis and management of inactive and asymptomatic hepatitis B virus carriers in Bangladesh. J Med Virol. 2010;82(8):1350-4.

13. Thomas HC. Immunological mechanisms in chronic hepatitis B infection. Hepatology. 1982;345:886-89.

14. Mukhopadhya A, Ramakrishna B, Richard V, Padankatti R, Eapen CE, Chandy GM. Liver histology and immunohistochemical findings in asymptomatic Indians with incidental detection of hepatitis B virus infection. Indian J Gastroenterol. 2006 ;25(3):128-31.

15. Chu CM, Liaw YF. Membrane staining for hepatitis B surface antigen on hepatocytes: a sensitive and specific marker of active viral replication in hepatitis B. J Clin Pathol. 1995;48:470-3.

16. Prati D, Taioli E, Zanella A et al. Updated definitions of healthy ranges for serum alanine aminotransferase levels. Ann Intern Med. 2002;137(1):1-10.

17. Piton A, Poynard T, Imbert-Bismut $F$ et al. Factors associated with serum alanine transaminase activity in healthy subjects: consequences for the definition of normal values, for selection of blood donors, and for patients with chronic hepatitis C. MULTIVIRC Group. Hepatology. 1998;27(5):1213-9.

18. Kim HC, Nam CM, Jee SH, Han KH, Oh DK, Suh I. Normal serum aminotransferase concentration and risk of mortality from liver diseases: prospective cohort study. BMJ. 2004;328(7446):983.

19. Wang C, Deubner H, Shuhart M et al. High prevalence of significant fibrosis in patients with immunotolerance to chronic hepatitis B infection. Hepatology. 2005;42(Suppl 1):A573.

20. Nguyen MH, Trinh H, Garcia RT et al. Significant histologic disease in HBV-infected patients with normal to minimally elevated ALT levels at initial evaluation. Hepatology. 2005;42(Suppl 1):A593.

21. Werle-Lapostolle B, Bowden S, Locarnini $\mathrm{S}$ et al. Persistence of cccDNA during the natural history of chronic hepatitis $\mathrm{B}$ and decline during adefovir dipivoxil therapy. Gastroenterology. 2004;126(7):1750-8.

22. Iloeje UH, Yang HI, Su J, Jen CL, You SL, Chen CJ. Risk Evaluation of Viral Load Elevation and Associated Liver Disease/Cancer-In HBV (the REVEAL-HBV) Study Group. Predicting cirrhosis risk based on the level of circulating hepatitis B viral load. Gastroenterology. 2006;130(3):678-86.

*Corresponding author:

Dr Puja Sakhuja, Head and Professor, Department of Pathology, Room no 327, 3rd floor, Academic block, Jawahar lal nehru marg, G B Pant Institute of Postgraduate Medical Education and Research, New Delhi, Pin 110002. INDIA

Phone: +919718599073

Email:pujasak@gmail.com

Date of Submission : 21.11.2016

Financial or other Competing Interests: None. 